\title{
Surgical aspects of endovascular retrograde implantation of the aortic CoreValve bioprosthesis in high-risk older patients with severe symptomatic aortic stenosis
}

Bertrand Marcheix, MD, MSc, ${ }^{a}$ Yoan Lamarche, MD, MSc, ${ }^{a}$ Colin Berry, MD, PhD, ${ }^{\mathrm{b}}$ Anita Asgar, MD, ${ }^{\mathrm{b}}$ Jean-Claude Laborde, MD, ${ }^{c}$ Arsène Basmadjian, MD, MSc, ${ }^{b}$ Anique Ducharme, MD, MSc, ${ }^{d}$ André Denault, MD, ${ }^{e}$ Raoul Bonan, $\mathrm{MD}^{\mathrm{b}}$ and Raymond Cartier, $\mathrm{MD}^{\mathrm{a}}$

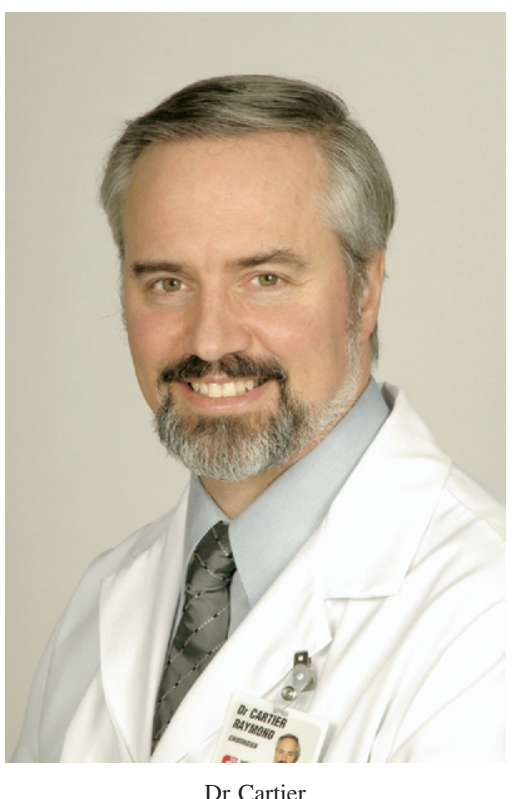

Dr Cartier
Objectives: Aortic stenosis is one of the most common forms of acquired valvular heart disease in adults, and the proportion of patients unsuitable for conventional surgery is increasing. Consequently, the development of new less-invasive techniques to treat severe aortic stenosis is crucially important. Current experience in percutaneous aortic valve replacement is limited to a few groups, and the search for an optimal technique continues. We report our experience with retrograde endovascular bioprosthesis implantation with brief cardiopulmonary bypass support in high-risk older patients.

Methods: The CoreValve pericardial bioprosthesis (CoreValve, Inc, Paris, France) is sutured on a nitinol frame and delivered in a $21 \mathrm{~F}$ catheter. All procedures were performed under femoro-femoral cardiopulmonary bypass support consisting of an aortic balloon valvuloplasty followed by prosthesis deployment within the aortic annulus under fluoroscopy. Ten high-risk surgical patients underwent percutaneous valve replacement.

Results: Immediate improvement in aortic valve function was observed in all patients. The aortic valve area increased from $0.57 \pm 0.19$ to $1.2 \pm 0.35 \mathrm{~cm}^{2}(P=$ $.00001)$, the mean transaortic valve gradient decreased from $51 \pm 19$ to $11 \pm 3 \mathrm{~mm}$ $\mathrm{Hg}(P<.001)$. The 30-day mortality was $20 \%$ : one patient died 5 days after the procedure of a massive ischemic stroke and 1 patient died at 20 days of a hemorrhagic stroke. The median New York Heart Association functional class improved from III to II $(P=.01)$.

Conclusions: Aortic valve replacement with the CoreValve bioprosthesis can be performed with favorable early technical results in high-risk patients. However, the morbidity and short-term mortality of such procedures remain significant.

\footnotetext{
From the Departments of Cardiovascular Surgery, ${ }^{\mathrm{a}}$ Cardiology, ${ }^{\mathrm{b}}$ and Anesthesiology, ${ }^{\mathrm{e}}$ Montreal Hear Institute and Université de Montréal, Montreal, Quebec, Canada; the Department of Interventional Cardiology, ${ }^{\mathrm{c}}$ Clinique Pasteur, Toulouse, France; and the Department of Anesthesiology, Montreal Heart Institute, Montreal, Quebec, Canada. ${ }^{\mathrm{d}}$

Drs Bonan and Laborde are consultants to CoreValve, Inc, Paris, France. Dr Berry was supported by a British Heart Foundation International Fellowship.

Received for publication Feb 9, 2007; revisions received July 3, 2007; accepted for publication July 10, 2007.

Address for reprints: Raymond Cartier, MD, Department of Cardiovascular Surgery, Montreal Heart Institute, 5000 Belanger Street, Montreal, Quebec H1T 1C8, Canada. (E-mail: rc2910@aol.com).

J Thorac Cardiovasc Surg 2007;134:1150-6

$0022-5223 / \$ 32.00$

Copyright (C) 2007 by The American Association for Thoracic Surgery

doi:10.1016/j.jtcvs.2007.07.031
} 


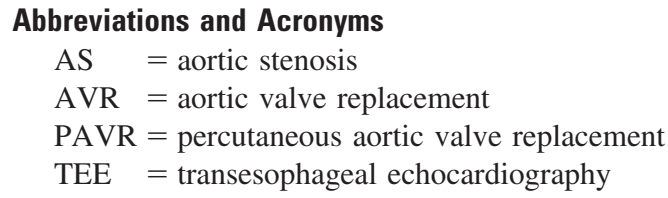

A ortic stenosis (AS) is one of the most common forms of acquired valvular heart disease in adults. $^{1,2}$ Open chest aortic valve replacement (AVR) is the "gold standard," improving survival and alleviating symptoms..$^{2-4}$ Nevertheless, the surgical approach is associated with substantial operative mortality rates in highrisk patients. Consequently, almost one third of patients with severe AS are not offered surgery owing to a combination of reasons such as advanced age, impaired left ventricular function, redo procedure, or multiple comorbidities. ${ }^{5}$ The prevalence of AS increases with age, ${ }^{2}$ and as longevity within the general population is increasing, the proportion of AS patients with contraindications for surgery is also expected to increase. Consequently, a less invasive and safer alternative to surgical aortic valve replacement for these patients is being increasingly recognized.

Balloon aortic valvuloplasty, originally described in the 1980 s, ${ }^{6}$ was the first alternative to surgical therapy. However, despite high rates of procedural success, restenosis led to disappointing results in the longer term in adult patients and has been abandoned. ${ }^{7}$ Recent success with percutaneous pulmonary valve implantation ${ }^{8}$ supports the possibility of percutaneous aortic valve replacement (PAVR). So far, early experience with this technique in humans is limited to a few devices. ${ }^{9-11}$

The optimal approach for PAVR continues to be investigated and several questions require clarification: method of approach (transaortic vs transapical), delivery catheter size, and circulatory support (cardiopulmonary bypass, temporary left ventricular assistance, or rapid ventricular pacing).

We report our early experience with a new endovascular technology allowing retrograde implantation with brief peripheral cardiopulmonary bypass support.

\section{Patients and Methods}

High-risk patients with severe symptomatic AS were referred for a percutaneous procedure because of a high or prohibitive risk with conventional surgery. The procedures were approved by the Therapeutic Products Directorate, Department of Health and Welfare, Ottawa, Canada, for compassionate clinical use in patients unsuitable for surgery. Informed written consent was obtained.

We reviewed our initial 9-month experience from December 2005 to August 2006. Patients underwent transthoracic echocardiography, iliofemoral contrast angiography, and coronary angiography. Clinical evaluation and echocardiograms (VIVID7; GE Healthcare, Milwaukee, Wis) were obtained before the procedure, within 24 hours of the procedure, at day 10, and at 1 month after the procedure.

\section{Prosthetic Valve System}

The CoreValve aortic valve prosthesis (CoreValve, Inc, Paris, France) consists of a single-size bioprosthetic valve made of porcine pericardial tissue, which is mounted and sutured in a self-expanding hourglass-shaped 55-mm length nitinol frame (Figure $1, A$ ). The lower part of the frame has a high radial force to overcome valvular calcification and prevent recoil, and it serves to anchor the prosthesis in the annulus. The mid part of the frame is constrained to avoid coronary ostia and carries the valve leaflets, whereas the upper part expands in the proximal ascending aorta to ensure stability and central alignment of the prosthesis. The actual valve inner diameter is $22 \mathrm{~mm}$. At the time of the procedure, the nitinol valve is chilled in cold saline and retracted into the $21 \mathrm{~F}$ delivery catheter by a compression and loading system.
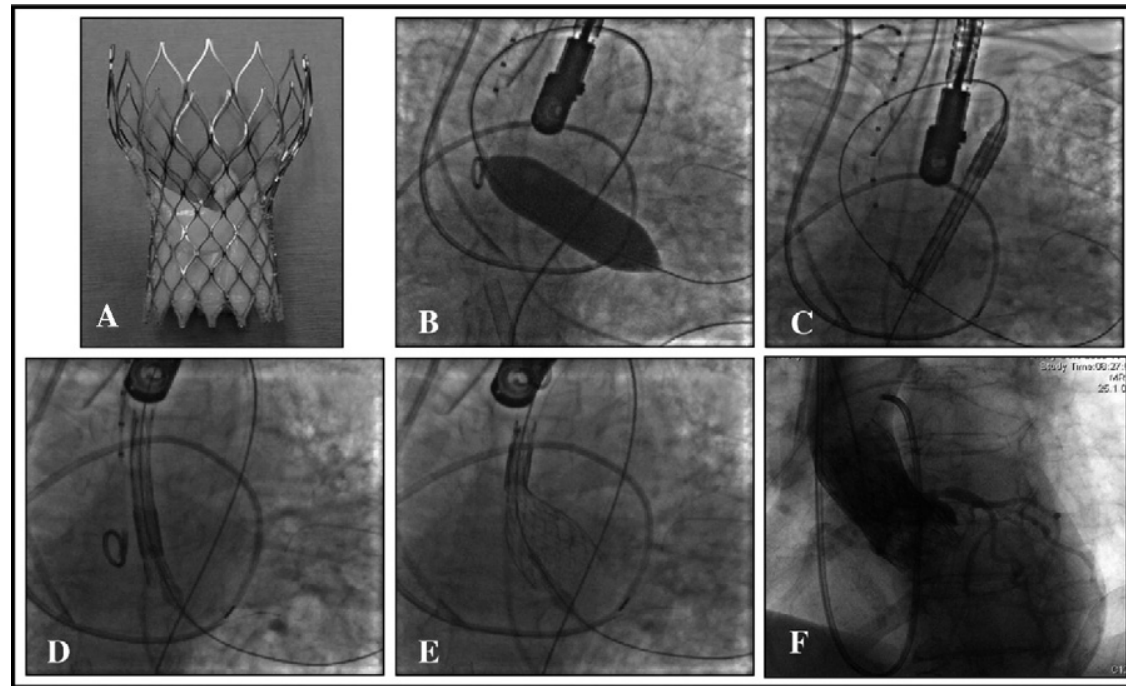

Figure 1. CoreValve percutaneous aortic prosthesis (A). Perioperative $x$-ray imaging demonstrating $23-\mathrm{mm}$ balloon dilatation of the stenotic aortic valve (B). Retrograde delivery catheter advancement toward the aortic arch and deployment of the prosthesis (C-E). A perioperative angiogram demonstrated excellent position and function of the bioprosthesis. The left and right coronary ostia are patent. There is no evidence of intraprosthetic or periprosthetic insufficiency (F). 


\section{Procedure}

The procedures were conducted in a sterile cardiologic interventional suite (Allura X per FD 10; Philips, Eindhoven, The Netherlands) in accordance with the World Health Organization's recommendations on air handling in surgical suites. The infrainguinal iliofemoral arterial junction was surgically exposed bilaterally. Through either right radial or brachial artery access, angiography of the ascending aorta was performed via a right anterior oblique view. After this, a straight Terumo Glidewire (Terumo Medical Corp, Somerset, NJ) was advanced through the iliofemoral arteriotomy and directed across the aortic valve with an Amplatz AL1 or AL2 diagnostic catheter (Cordis Corp, Miami, Fla). This wire was then exchanged for a 0.035-inch Amplatz Extra Stiff (Boston Scientific, Natick, Mass) guidewire to maintain a secure wire position within the left ventricle. The patient was heparinized (3 $\mathrm{mg} / \mathrm{kg})$, and then venous $(21 \mathrm{~F}-23 \mathrm{~F})$ and arterial femoral canulas (17F or 19F) were inserted, permitting femoro-femoral cardiopulmonary bypass. Transesophageal echocardiography (TEE) and fluoroscopy were used to optimize venous cannula positioning in the right atrium during cardiopulmonary bypass. Valvuloplasty with a $23 \mathrm{~F}$ balloon catheter (Numed, Hopkinton, NY) was first performed to optimize the valve area (Figure 1, B). After this, a delivery catheter was advanced under fluoroscopic guidance (Figure 1, $C$ and $D$ ). The prosthesis was positioned with its distal third adjacent to the calcified native leaflets under fluoroscopy. The prosthesis was deployed by careful retraction of the delivery sheath (Figure 1, $E$ and $F$ ). Angiograms and TEE were systematically performed to verify the position and competent function of the prosthesis, as well as the patency of the coronary ostia. If significant periprosthetic leaks occurred immediately after PAVR, intraprosthetic balloon dilatation was performed to achieve an optimal seal with the aortic annulus. Cardiopumonary bypass was then progressively weaned, followed by removal of the sheath and cannulas and reversal of heparin.

\section{Preoperative and Postoperative Care}

All patients received either vancomycin or cefazolin intravenously (1 g) immediately before the procedure. Antibiotic prophylaxis was systematicaly continued for 48 hours. Combination therapy with aspirin (325 mg) and clopidogrel (300 mg loading dose followed by $75 \mathrm{mg}$ daily maintenance dose) was started preoperatively and given after the procedure for 3 months. Aspirin $(80 \mathrm{mg}$ daily) monotherapy was then continued indefinitely. Low-dose subcutaneous heparin (5000 IU twice daily) was administered for thromboprophylaxis until patients were ambulatory.

\section{Statistical Analyses}

Continuous normally distributed variables are expressed as mean \pm SD and analyzed by the paired Student $t$ tests or analysis of variance. Continuous non-normally distributed data are expressed as median (interquartile range) and analyzed with a Wilcoxon or Kruskal-Wallis test Categorical data were analyzed by a Pearson $\chi^{2}$ test. All statistical analyses were undertaken with StataCorp version 7 software (StataCorp, College Station, Tex). Adjustments were not made for multiple testing.
TABLE 1. Preoperative characteristics of 10 patients

\begin{tabular}{|c|c|}
\hline Mean age (y) & 81.3 (range 64-85) \\
\hline Male gender, $\mathrm{n}(\%)$ & $5(50)$ \\
\hline Coronary artery disease, $\mathrm{n}(\%)$ & $6(60)$ \\
\hline LV systolic dysfunction (EF $\leq 30 \%), \mathrm{n}(\%)$ & $4(40)$ \\
\hline Mean (SD) EF (\%) & $48 \pm 18$ \\
\hline Prior or current smoking, $\mathrm{n}(\%)$ & $2(20)$ \\
\hline $\mathrm{COPD}^{*} \mathrm{n}(\%)$ & $6(60)$ \\
\hline NYHA functional class, median (range) & $3(3,4)$ \\
\hline Diabetes mellitus, $\mathrm{n}(\%)$ & $3(30)$ \\
\hline Hypertension, n (\%) & $7(70)$ \\
\hline Renal insufficiency, $†$ n (\%) & $7(70)$ \\
\hline Peripheral vascular disease, $\neq \mathrm{n}(\%)$ & $6(60)$ \\
\hline Carotid artery disease, $\mathrm{n}(\%)$ & $5(50)$ \\
\hline \multicolumn{2}{|l|}{ Prior cardiac surgery, $\mathrm{n}(\%)$ types: } \\
\hline MVR & $1(10)$ \\
\hline CABG & $3(30)$ \\
\hline Chronic atrial fibrillation, $\mathrm{n}(\%)$ & $4(40)$ \\
\hline Permanent pacemaker, n (\%) & $3(30)$ \\
\hline Pulmonary hypertension,§ n (\%) & $8(80)$ \\
\hline PASP $\geq 30 \mathrm{mmHg}<60 \mathrm{mmHg}$ & $3(30)$ \\
\hline PASP $\geq 60<90 \mathrm{mmHg}$ & $5(30)$ \\
\hline Preoperative aspirin use, median (range) & $4(4-4)$ \\
\hline Parsonnet score & $31.6 \pm 7.3$ \\
\hline Parsonnet predicted mortality & $22.9 \pm 15.3$ \\
\hline $\begin{array}{l}\text { Logistic EuroSCORE, median (interquartile } \\
\text { range) }\end{array}$ & $32 \%(21 \%-40 \%)$ \\
\hline Logistic EuroSCORE $>20 \%$ & $8(80 \%)$ \\
\hline
\end{tabular}

$L V$, Left ventricular; $E F$, ejection fraction; $S D$, standard deviation; $C O P D$, chronic obstructive pulmonary disease; NYHA, New York Heart Association; $M V R$, mitral valve replacement; $C A B G$, coronary artery bypass grafting; $P A S P$, pulmonary artery systolic pressure. ${ }^{*}$ Chronic obstructive pulmonary disease $=$ a history of respiratory problems associated with maintentance inhaled bronchodilator therapy and forced expiratory volume in 1 second $<50 \%$. tRenal insufficiency = serum creatinine concentration (clearance of creatinine $<40 \mathrm{~mL} / \mathrm{min}$ ). $\ddagger$ Peripheral vascular disease is defined by a history of symptomatic claudication or angiographic evidence of peripheral vascular disease. §Pulmonary hypertension = pulmonary artery systolic pressure $>25 \mathrm{~mm} \mathrm{Hg}$

\section{Results \\ Patients}

PAVR with full cardiopulmonary bypass was performed in 10 patients with severe symptomatic AS between December 2005 and August 2006. Patients' pre-procedural characteristics are shown in Table 1. Three patients were in New York Heart Association class IV and the others were in class III $(n=7)$. Nine patients were 80 years old or more. All patients had been deemed by at least two cardiothoracic surgeons to be at prohibitively high surgical risk for conventional open chest AVR. The predicted mortality rates if conventional procedures were performed were $22.9 \% \pm$ $15.3 \%$ and $32 \%(21 \%-40 \%)$, respectively, according to the Parsonnet and logistic EuroSCORE preoperative risk estimation scores. Specific contraindications for surgery are listed in Table 2. 
TABLE 2. Specific contraindications for surgery

\begin{tabular}{cccl}
\hline Patient & Gender & Age & \multicolumn{1}{c}{ Patient comorbidity } \\
\hline 1 & F & 64 & Pulmonary fibrosis; FEV 1 =0.4 \\
2 & F & 85 & Severe COPD* \\
3 & M & 80 & PVD; prior CABG \\
4 & F & 82 & Connective tissue disease \\
5 & F & 81 & Severe COPD; cardiac cachexia; \\
& & & kyphoscoliosis \\
6 & M & 84 & Severe heart failure; cachexia \\
7 & M & 85 & PVD; severe COPD \\
8 & M & 83 & Severe COPD \\
9 & M & 85 & Prior CABG, renal failure \\
10 & F & 84 & Prior MVR; severe COPD*
\end{tabular}

$\overline{F E V}{ }_{1}$, Forced expiratory volume in 1 second; $C O P D$, chronic obstructive pulmonary disease; $P V D$, peripheral vascular disease; $C A B G$, coronary artery bypass grafting; $M V R$, mitral valve replacement. ${ }^{*} \mathrm{FEV}_{1}<50 \%$ (rejected in surgery by 2 surgeons).

\section{Procedures}

Valvuloplasty, delivery catheter positioning, and bioprosthetic valve deployment were successful in all patients. No patient died during the procedure and no patient required conversion to a conventional open chest procedure (Table $3)$. Mean procedure time was $3.2 \pm 0.9$ hours.

Positioning of the venous cannula in the right atrium and the efficiency of the venous return were assessed with TEE and fluoroscopy. Vacuum-assisted venous return was used if necessary $(20-40 \mathrm{~mm} \mathrm{Hg})$. Median cardiopulmonary bypass time was 28 minutes (range: 19-83 minutes). One patient underwent a combined procedure with angioplasty and stent implantation for a tight stenosis of the left anterior descending artery and AVR. Two patients required percutaneous angioplasty of the common iliac artery to allow progression of the sheath. In one 85-year-old patient (patient 7), after percutaneous angioplasty and successful placement of the prosthesis, periprocedural TEE identified a large atherosclerotic plaque in the left ventricular outflow tract. The debris was retrieved with an endovascular bioptome and ex vivo analysis confirmed the tissue to be vascular, most likely iliac artery tissue displaced by delivery catheter advancement. The procedure was complicated by a hemopericardium (owing to the bioptome manipulation) that required emergency pericardiocentesis. The patient subsequently experienced hemorrhagic shock in the early postoperative period, and surgical exploration of the abdomen identified hepatic trauma and intraperitoneal hemorrhage.

\section{Postoperative Course}

Mean mechanical ventilation time was $7.8 \pm 4.7$ hours. All patients had mild transient elevation of creatine kinase MB and troponin $\mathrm{T}$ as indicated in Table 3. The operative (30-day) mortality was $20 \%$ and hospital mortality was $30 \%$ (including operative mortality). Postoperative complica-
TABLE 3. Procedures and postoperative course

\begin{tabular}{|c|c|}
\hline \multicolumn{2}{|l|}{ Procedural outcomes } \\
\hline Successful valvuloplasty, n (\%) & $10(100)$ \\
\hline Successful prosthesis implantation, n (\%) & $10(100)$ \\
\hline $\begin{array}{l}\text { Combined procedure (coronary angioplasty + } \\
\qquad \text { AVR, } n(\%)\end{array}$ & $1(10)$ \\
\hline Perioperative peripheral artery angioplasty, $\mathrm{n}(\%)$ & $2(20)$ \\
\hline \multicolumn{2}{|l|}{ Postprocedural outcomes } \\
\hline Blood transfusion $>2$ units, $\mathrm{n}(\%)$ & $6(60)$ \\
\hline Mean (SD) mechanical ventilation time, $\mathrm{h}$ & $7.8 \pm 4.7$ \\
\hline Mean (SD) ICU stay, d & $4.6 \pm 2.2$ \\
\hline Mean (SD) hospital stay, d & $15 \pm 12$ \\
\hline Day 0 & $11.4 \pm 4.9$ \\
\hline Day 1 & $26.5 \pm 27.9$ \\
\hline Day 2 & $14.1 \pm 11.8$ \\
\hline $\begin{array}{l}\text { Myocardial infarction (CK MB }>100 \mathrm{mg} / \mathrm{L} \text { or } \\
\text { new } 0 \text { wave, } \mathrm{n}(\%)\end{array}$ & 0 \\
\hline \multicolumn{2}{|l|}{ Mean (SD) troponin T concentration* $(\mu \mathrm{g} / \mathrm{L})$} \\
\hline Day 0 & $0.54 \pm 0.7$ \\
\hline Day 1 & $0.5 \pm 0.4$ \\
\hline Day 2 & $0.96 \pm 0.92$ \\
\hline Death $<30 \mathrm{~d}$ & $2(20)$ \\
\hline Stroke, n $(\%)$ & $2(20)$ \\
\hline New permanent pacemaker implantation, n (\%) & $3(30)$ \\
\hline $\begin{array}{l}\text { Acute renal failure requiring temporary renal } \\
\text { replacement therapy, } \mathrm{n}(\%)\end{array}$ & $1(10)$ \\
\hline Nonsustained atrial fibrillation, n (\%) & $2(20)$ \\
\hline Major bleeding, n (\%) & $2(20)$ \\
\hline Vascular access site complication, $† \mathrm{n}(\%)$ & $3(30)$ \\
\hline Confusion, $\mathrm{n}(\%)$ & $3(30)$ \\
\hline Respiratory tract infection, n (\%) & $1(10)$ \\
\hline
\end{tabular}

$A V R$, Aortic valve replacement; $S D$, standard deviation; $I C U$, intensive care unit; $C K M B$, creatine kinase $\mathrm{MB}$. ${ }^{*}$ Cardiac biomarker reference ranges: creatinine kinase $\mathrm{MB}$ mass $0-5 \mathrm{mg} / \mathrm{L}$; troponin $\mathrm{T}$ 0-0.03 $\mu / \mathrm{L}$. †Hematoma, $\mathrm{n}=2$; lymphorrhea, $\mathrm{n}=1$; infection, $\mathrm{n}=1$ (1 patient had a hematoma and a wound infection).

tions are shown in Table 3. Patient 7 died on the fifth postoperative day after a massive hemispheric ischemic stroke. One patient had a postoperative ophthalmoplegia related to an embolic event. Three other patients had transient confusion without computed tomographic evidence of cerebral embolization. Two patients required pacemaker implantation because of persistent atrioventricular block. Two patients had transient nonsustained atrial fibrillation. Vascular access complications were encountered in 5 patients: 1 had a hematoma, 2 had lymphoceles, and 2 required femoral arterial reconstructions (patch angioplasty). Femoral wound infection was encountered in 1 patient with bilateral lymphoceles. Two patients required reoperation, 1 (patient 7) because of intra-abdominal bleeding related to pericardial (and inadvertent hepatic) puncture (patient 7) and another for an infected inguinal lymphocele. The mean intensive care unit stay was $4.6 \pm 2.2$ days and the mean hospital stay was $15 \pm 12$ days. 

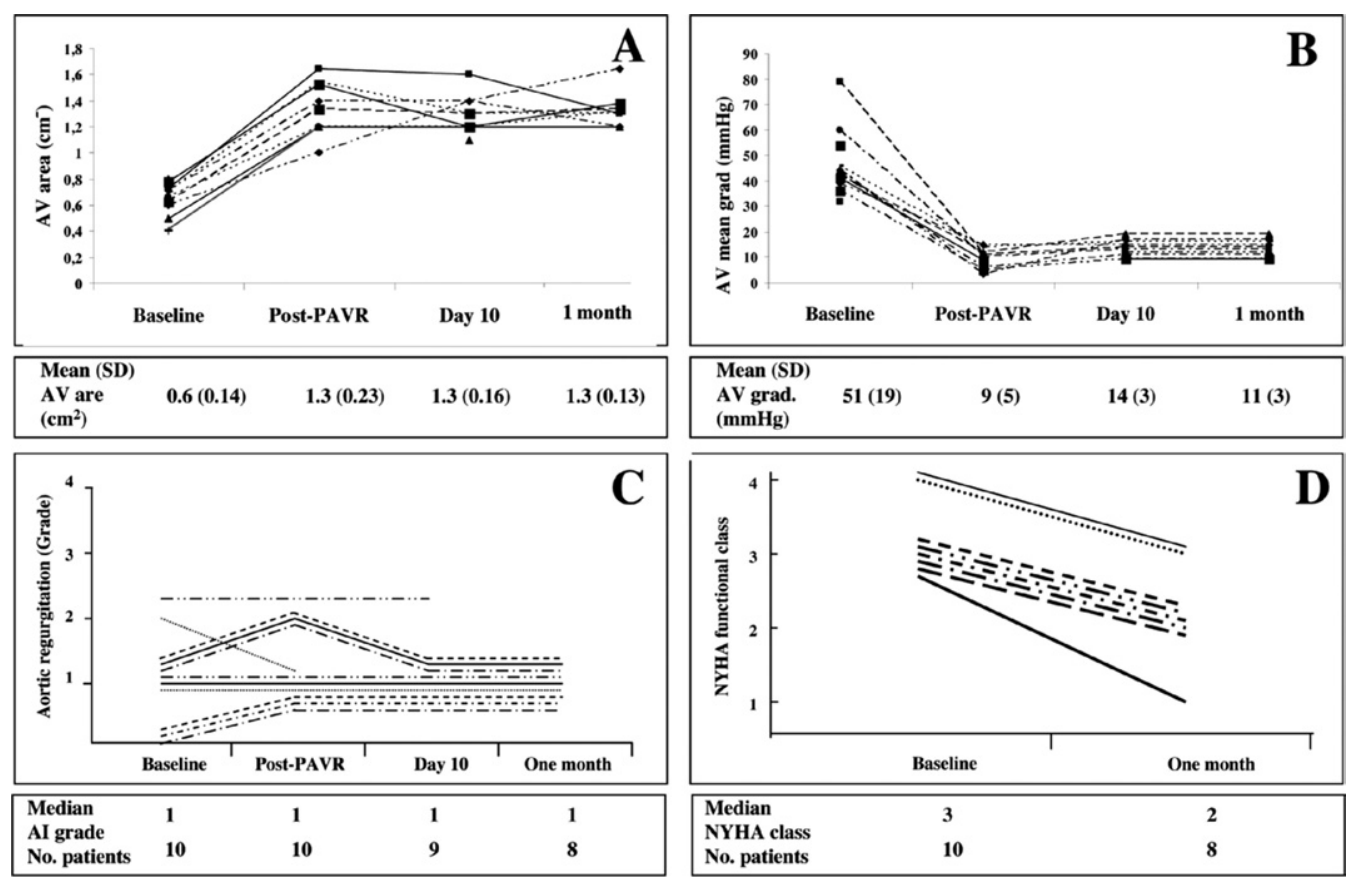

Figure 2. Improvements in the aortic valve (AV) area (A) and mean transaortic gradient after endovascular AVR (B). Aortic valve regurgitation remained mild ( $\leq$ grade 2 , and $\leq$ grade 1 in most) immediately after AVR and during follow-up (C). Improvement in New York Heart Association (NYHA) functional class (D). Each curve represents the data for 1 patient. PAVR, Percutaneous aortic valve replacement; Al, aortic insufficiency; SD, standard deviation.

\section{Perioperative Prosthesis Evaluation}

The prosthesis was assessed at the end of each procedure by utilizing TEE and angiography. Immediate improvement in aortic valve function was observed in all patients. The aortic valve area increased from $0.57 \pm 0.19$ to $1.2 \pm 0.35 \mathrm{~cm}^{2}(P$ $=.00001)($ Figure $2, A)$ and the mean transaortic valve gradient decreased from $51 \pm 19$ to $11 \pm 3 \mathrm{~mm} \mathrm{Hg}(P<$ .001) (Figure 2, B). Five patients had mild intraprosthetic insufficiency $(<1)$ and 8 patients had a mild-to-moderate periprosthetic leak (grade $1 / 4[\mathrm{n}=7]$ or $2 / 4[\mathrm{n}=1]$; Figure 2,C). Perivalvular leak remained stable over the first month.

\section{Follow-up (1 Month)}

One patient had an intracerebral hemorrhage on day 20 and died. New York Heart Association class improved by at least one point in all surviving patients (Figure 2, D). No patient had any hemolysis or evidence of endocarditis, and no patient required any reintervention for valve dysfunction or any hospital readmission. The 3-month mortality was $30 \%$ and our first patient remains well more than 16 months after the procedure. The 3-month mortality was $30 \%$ and our first patient remains well more than 16 months after the procedure.

\section{Postmortem Prosthesis Assessment}

An autopsy was performed in the patient who died on day 5 (patient 7). Postmortem assessment confirmed good prosthetic valve position and function and found no evidence of any device-related complication. The coronary ostia were patent.

\section{Discussion}

We report the initial Montreal Heart Institute experience with endovascular implantation of a self-expanding aortic valve prosthesis. We have confirmed that implantation of the prosthesis is feasible, leading to an immediate increase in the valve surface area and a decrease in the transaortic mean gradient. Although every patient had a minor degree of aortic regurgitation, it remained mild to moderate ( $\leq$ grade 2 and $\leq$ grade 1 in most) in all cases. Short-term follow-up in survivors confirmed that these initial results were maintained. None of the patients had problems as a result of unstable coronary artery disease during follow-up. These results confirm the potential for safe and effective PAVR.

Our approach differs from the Cribier-Edwards LifeSciences system in several important ways. By contrast with this latter balloon-expandable stent prosthesis, ${ }^{12,13}$ the device used in this series is a self-expanding aortic valve 
prosthesis designed for retrograde implantation via the arterial iliofemoral arteries. Whereas animal studies have shown that the balloon-expandable prosthesis requires exact device positioning to avoid device embolization, ${ }^{14}$ the longer profile and self-expandable properties of nitinol could enhance the stability once deployed. ${ }^{15}$ Even though nitinol devices could be susceptible to fracture with time, the same self-expandable technology is commonly used in thoracic aortic stent grafts and has shown good midterm results. ${ }^{16}$ After device deployment, intraprosthetic balloon expansion can also be performed to minimize periprosthetic regurgitation but is seldom required.

Mild-to-severe paravalvular aortic regurgitation has been observed in most patients who have undergone percutaneous implantation of the balloon-expandable valve prosthesis. ${ }^{17}$ One possible advantage of a self-expanding prosthesis is the potential for continued expansion over time, which may in turn reduce paravalvular leaks after implantation. ${ }^{15}$

One theoretical advantage of the antegrade approach is a lower risk of atheroma embolism during delivery catheter advancement through an atheromatous aorta. Nevertheless, the need for transseptal puncture, unavoidable traction on the anterior mitral valve leaflet inducing potentially severe mitral regurgitation, and hemodynamic instability constitute the main drawbacks of this approach. ${ }^{15,18}$ Emerging advances in percutaneous procedures include reduced delivery catheter size (ie, $18 \mathrm{~F}$ delivery system) and alternative approaches (retrograde subclavian or transapical approaches), which may reduce the risk of implantation failure in patients with severe peripheral vascular disease. These new approaches may limit the risk of femoral access site complication.

The relatively brief cardiopulmonary bypass times in this series were sufficient to unload the left heart cavities, ensure hemodynamic stability, and secure the release of the prosthesis in the correct position. Circulatory support may represents a safer alternative to brief rapid cardiac pacing (200-220 beats/min) in patients with severe AS and left ventricular hypertrophy inasmuch as low cardiac output may lead to myocardial ischemia and subsequent hemodynamic instability. Therefore, this was chosen as our method of choice for the beginning of our experience with endovascular replacement of the aortic valve.

The mortality rate observed in our series was similar to that which was predicted using the Parsonnet and EuroSCOREs (20\% vs 23\%-24\%). Three patients were not candidates for surgery and the others were deemed to be very poor candidates for conventional surgery. Two had severe lung disease prohibiting any kind of thoracic exploration and 1 had severe kyphoscoliosis making a classic operative approach impossible. Other scoring systems may help to obtain a better stratification and uniform preoperative risk reporting for endovascular aortic replacement in the future. ${ }^{19}$

The high 1-month mortality was associated with neurologic complications in 2 patients. These complications could possibly be prevented by alternate vascular access in patients with peripheral vascular disease. However, the hemorrhagic stroke at 20 days can be related to the anticoagulation regimen; this was adjusted for the following patients. These comorbidities and the complex postprocedural support needed for these patients before discharge are reflected by a prolonged hospital stay. Long-term follow-up of our patients is ongoing. Immediate improvements of the aortic valve surface area were observed in all patients, device-related complications did not occur, and New York Heart Association functional class improved in all patients, despite their comorbidities.

As reported in aortic endovascular interventions, the main risks for this type of procedure are also embolic stroke and technical problems related to peripheral vascular disease. ${ }^{20}$ The significant length of hospital stay in our patients indicates their complex postprocedural supportive needs before discharge.

\section{Conclusions}

Endovascular AVR with a self-expandable bioprosthesis can be performed with favorable immediate results in a cohort of older and high-risk surgical patients. However, the short-term mortality of these patients remains high, most likely due to significant comorbidity. Notably, neurovascular complications are an important postprocedural complication. Prospective studies involving larger numbers of high-risk surgical patients are required to evaluate the potential utility of this emerging and promising technology.

\section{References}

1. Iung B, Baron G, Butchart EG, Delahaye F, Gohlke-Barwolf C, Levang OW, et al. A prospective survey of patients with valvular heart disease in Europe: The Euro Heart Survey on Valvular Heart Disease. Eur Heart J. 2003;24:1231-43.

2. Nkomo VT, Gardin JM, Skelton TN, Gottdiener JS, Scott CG, Enriquez-Sarano M. Burden of valvular heart diseases: a populationbased study. Lancet. 2006;368:1005-11.

3. Kvidal P, Bergstrom R, Horte LG, Stahle E. Observed and relative survival after aortic valve replacement. J Am Coll Cardiol. 2000;35: 747-56.

4. Schwarz F, Baumann P, Manthey J, Hoffmann M, Schuler G, Mehmel $\mathrm{HC}$, et al. The effect of aortic valve replacement on survival. Circulation. 1982;66:1105-10.

5. Iung B, Cachier A, Baron G, Messika-Zeitoun D, Delahaye F, Tornos $\mathrm{P}$, et al. Decision-making in elderly patients with severe aortic stenosis: why are so many denied surgery? Eur Heart J. 2005;26:2714-20.

6. Cribier A, Saoudi N, Berland J, Savin T, Rocha P, Letac B. Percutaneous trans-luminal valvuloplasty of acquired aortic-stenosis in elderly patients-alternative to valve-replacement. Lancet. 1986;1:63-7.

7. Eltchaninoff H, Cribier A, Tron C, Anselme F, Koning R, Soyer R, et al. Balloon aortic valvuloplasty in elderly patients at high-risk for surgery, or inoperable-immediate and mid-term results. Eur Heart J. 1995;16:1079-84 
8. Bonhoeffer P, Boudjemline Y, Saliba Z, Merckx J, Aggoun Y, Bonnet $\mathrm{D}$, et al. Percutaneous replacement of pulmonary valve in a rightventricle to pulmonary-artery prosthetic conduit with valve dysfunction. Lancet. 2000;356:1403-5.

9. Berry C, Lamarche Y, Laborde JC, Cartier R, Denault A, Basmadjian A, et al. First case of combined percutaneous aortic valve replacement and coronary artery revascularisation. EuroIntervention. 2006;2: 257-61.

10. Grube E, Laborde JC, Zickmann B, Gerckens U, Felderhoff T, Sauren B, et al. First report on a human percutaneous transluminal implantation of a self-expanding valve prosthesis for interventional treatment of aortic valve. Catheter Cardiovasc Interv. 2005;66:465-9.

11. Lamarche Y, Berry C, Cartier R, Denault A, Basmadjian A, Laborde JC, et al. First North American implantation of the CoreValve percutaneous aortic valve. Ann Thorac Surg. 2007;83:284-7.

12. Lichtenstein S, Cheung A, Ye J, Thompson CR, Carere RG, Pasupati $\mathrm{S}$, et al. Transapical transcatheter aortic valve implantation in humans. Initial clinical experience. Circulation. 2006;114:591-6.

13. Webb JG, Chandavimol M, Thompson CR, Ricci DR, Carere RG, Munt BI, et al. Percutaneous aortic valve implantation retrograde from the femoral artery. Circulation. 2006;113:842-50.
14. Boudjemline Y, Bunhoeffer D. Steps toward percutaneous aortic valve replacement. Circulation. 2002;105:775-8.

15. Laborde JC, Borenstein N, Behr L, Farah B, Fajadet J. Percutaneous implantation of an aortic valve prosthesis. Catheter Cardiovasc Interv. 2005;65:171-4

16. Sunder-Plassmann L, Scharrer-Pamler R, Liewald F, Kapfer X, Gorich J, Orend KH. Endovascular exclusion of thoracic aortic aneurysms: mid-term results of elective treatment and in contained rupture. J Card Surg. 2003;18:367-74.

17. Cribier A, Eltchaninoff H, Tron C, Bauer F, Agatiello C, Sebagh L, et al. Early experience with percutaneous transcatheter implantation of heart valve prosthesis for the treatment of end-stage inoperable patients with calcific aortic stenosis. J Am Coll Cardiol. 2004;43:698-703.

18. Webb JG, Munt B, Makkar RR, Naqvi TZ, Dang N. Percutaneous stent-mounted valve for treatment of aortic or pulmonary valve disease. Catheter Cardiovasc Interv. 2004;63:89-93.

19. Hannan E, Wu C, Bennett EV, Carlson RE, Culliford AT, Gold JP, et al. Risk index for predicting in-hospital mortality for cardiac valve surgery. Ann Thorac Surg. 2007;83:921-30.

20. Berry C, Cartier R, Bonan R. Fatal ischemic stroke related to nonpermissive peripheral artery access for percutaneous aortic valve replacement. Catheter Cardiovasc Interv. 2007;69:56-63.

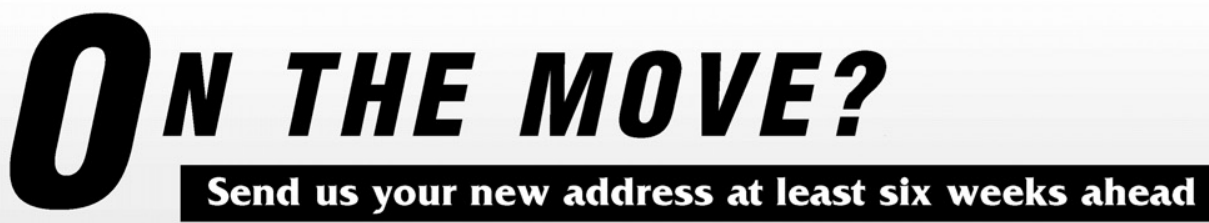

Don't miss a single issue of the journal! To ensure prompt service when you change your address, please photocopy and complete the form below.

Please send your change of address notification at least six weeks before your move to ensure continued service. We regret we cannot guarantee replacement of issues missed due to late notification.

\section{JOURNAL TITLE:}

Fill in the title of the journal here.

\section{OLD ADDRESS:}

Affix the address label from a recent issue of the journal here.

\section{NEW ADDRESS:}

Clearly print your new address here.

Name

Address

City/State/ZIP
COPY AND MAIL THIS FORM TO:

Elsevier Inc.

Subscription Customer Service

6277 Sea Harbor Dr

Orlando, FL 32887
OR FAX TO:

407-363-9661

OR E-mail:

elspcs@elsevier.com
OR PHONE:

800-654-2452

Outside the U.S., call

407-345-4000 